\title{
Rapid World Development Method to Increase Web3D Implementation
}

\author{
Mursid W. Hananto \\ Department of Information Systems \\ Universitas Ahmad Dahlan \\ Yogyakarta, Indonesia
}

\author{
Khabib Mustofa \\ Department of Computer \\ Science and Electronics \\ Universitas Gadjah Mada \\ Yogyakarta, Indonesia
}

\begin{abstract}
Implementation of Web3D technologies on the Internet today apparently not much been done by enthusiasts or beginners in this field. One reason is the difficulty to undertake one of the important steps in it, that is, building the visual scenery which is also called the world. If the object is complex or increasingly detailed, it will be increasingly difficult to make its digital representation in the form of $3 \mathrm{D}$ object, especially when it is desired to resemble the original real-world object. Utilization of modeling software can help the developers to cut the difficulty and development time, but the modeling software will generate a document file which can not be directly published online by first time developers or beginners who do not have a deep understanding on the document format they use. A guide is required for them so that they can quickly produce the world they need and ready to be published. The method proposed in this paper assumes the prospective developers use $3 \mathrm{D}$ modeling software that can export the resulting world to a Web3D standard format. The emphasis of this method is to assist the developers so that they can produce a world deserves to be accessed by users on the Internet, in a short time.
\end{abstract}

\section{General Terms}

Visualization and Multimedia, Internet and Distributed Computer Systems, Graphics and Imaging.

\section{Keywords}

Web3D, rapid, world, development, method.

\section{INTRODUCTION}

Web3D which is intended to complement and not replace conventional web at the moment is still not widely implemented as many as conventional web. By way of 3D browsing, users will actually be able to realize the actual virtual space, not just switching display from one flat document to another document. With Web3D, users can browse the web as they explore the real world. Interaction with other online users will be even greater, so browsing on the Internet will provide a more enjoyable experience.

Due to the nature of interaction with users that increasingly widespread, the form of web interface can be more varied. From the site the which includes infrastructure in an area such as Getty Museum at Los Angeles [1] and Rodeo Drive at Beverly Hills [2], restoration of heritage sites The Temple of Ikaros [3], or virtual city of Ljubljana [4], to sites that display information in a way that is unique with innovative visualization ie. [5] which was built by Ivan Klima. In addition there is Amarna Virtual Museum [6] which is one of the virtual museum that apply Web3D as part of their online representations. Generally, the spectrum of Web3D applications is very broad. They can be grouped as services, e- business, education and training, tele maintenance, data visualization, and entertainment [7].

Various concepts can be utilized for Web3D sites with specific purposes, such as the use of Web3D in the virtual museum [8], as well as in the field of education as in [9], or in the medical field as in [10] and [11]. For all those implementations, there is a need for a thorough development method which can become an umbrella for all development activities in order to have a proper sequence of steps, so that the built implementations can suit the needs. Among many methods for web developments, there is a method expressed by Mark Pesce [12], one of the early pioneers of Web3D technology, in Fig. 1. The method has sequence of steps which was addressed to meet the special needs of the Web3D development.

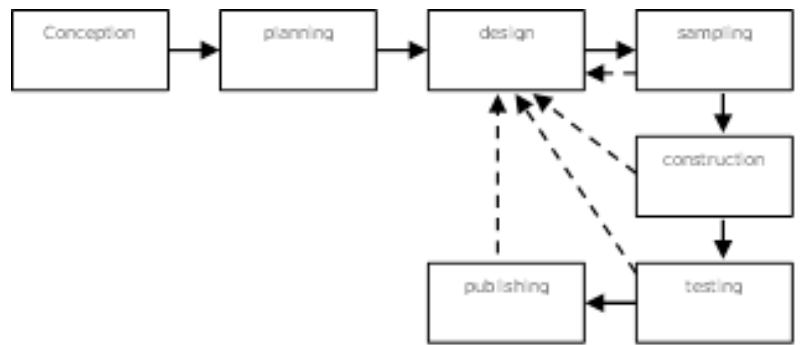

Fig 1: Development method for Web3D site/applications

[12]

Even though there has been a method that is devoted to the development of Web3D site or its application in overall, but there is no more in-depth detail on one of the most important steps in the method, that is, the Construction phase. Construction phase is the step which produces the real product of Web3D that can be seen by users. The method that can be a guideline devoted for building the world in Web3D is not yet available. World is a term for a display similar to the conventional web page. World visually shows the contents of Web3D sites which can be accessed by the users by way of a specific interaction. World can respond to input of almost any form [13]. To be able to implement the Web3D technologies, a medium is necessary to realize the world in the form of a document. The absence of specific methods that could serve as guidelines for developers to build a world make the development work become very difficult and it took a long time to be resolved, especially for sites which have content that can be called large-sized and has a high complexity in terms of the quantity of both navigational and visual detail. This paper discusses about the proposed method which is intended to prepare the documents required by Web3D developer so they can quickly build world with the constituent documents which eligible to be published on the Internet. 


\section{WORLD DEVELOPMENT}

As in conventional 2D web, in order to build a world, there is a need for documents which contain everything to be displayed in the browser. The document is created in a particular format which contains a description of the view of the world. Among the variety of document formats that exist today, VRML \& X3D are the formats issued by the Web3D Consortium. Both formats have become official standard in Web3D. VRML was the first standard, assigned by the standard number ISO/IEC 14772 [14], implemented by earlier Web3D sites. Standard VRML version set by Web3D Consortium is VRML97 [15]. X3D also has become a standard promulgated by the Web3D consortium [16], and became the successor to VRML with various additions so it makes the format even better. One of the advantages of standard formats is the easiness to read and write. This is because VRML uses the ASCII character set [17], as well as $\mathrm{X} 3 \mathrm{D}$. Therefore, prospective developers do not have to use a special application because they can use a variety of text editors available today to create 3D objects and build a world contains a set of 3D objects.

The difficulty of building the world become one of the obstacles in implementing the Web3D. Creating 3D models especially complex models followed by building a whole complete world is the first step in implementing Web3D. Prospective developers especially those who are beginners will generally feel overwhelmed with the syntax of VRML and X3D. X3D written using XML style [18] can not be easily understood by developers who are still beginners even though $\mathrm{XML}$ is a simple, generic format for structured data that has been standardized by the World-Wide Web Consortium [19]. Although X3D can also be written using VRML style [20], it does not make it easier to use. Consequently, these barriers become a big problem for enthusiasts and prospective site developers which use Web3D technology. Since the encoding method is not easily understood as in HTML, it will make those who want to switch to 3D-style in the web cancel their intention and stay on 2D-only course.

The problem is getting bigger as real-world objects are generally so difficult to be realized in the form of digital 3D models since they have high details and complexities. This makes it increasingly unlikely to develop worlds with only a text editor. Some have tried to address this problem by developing world document editor software, for VRML format as well as X3D. Such tools for this purpose are VRMLPad [21] dan X3Dedit [22]. In practice, using these specific editors needs a lot of learning time, and the difficulty level is quite steep for many beginners as both tools require deep understanding on the particular format they are about to use.

Creating worlds using standard format indeed can be done without any support of particular editor tools, but it will take a long time to create complex worlds. Nowadays, some 3D modeling softwares have the support for this format in the form of VRML exporter [23]. This is very helpful in the development process especially when creating complex world with large number of objects used in the scene. One of 3D modeling softwares which has the ability to assist in making a Web3D world is 3DS Max [24]. Even so, using the modeling software as the main supporting tool for Web3D development has given raise to a new problem, that is, the exported file as the result of using such tools is a single document file that contains all scene descriptions.
Such world which created from a single file containing all the objects directly produced by modeling software is not feasible to be use for Web3D sites, it needs some further post processing as adjustments. For a world with a simple object, then the converted file size is surely small. If the $3 \mathrm{D}$ model that will be built are enormous in size and detail, then the resulting single file can reach the size of hundreds of MegaBytes. Users will not be able to put down this single file on the internet because it is too big, so it is not feasible as a world to be published online.

\section{PROPOSED METHOD}

To facilitate the prospective potential developers who do not have deep understanding on Web3D document, it is necessary to provide a development method which is specific and clear in a series of world development procedures. Process sequence which is formed into these development methods can be used as a guide so that users can immediately produce world eligible to be published on the internet. Briefly, sequence of the procedures is shown in Fig. 2.

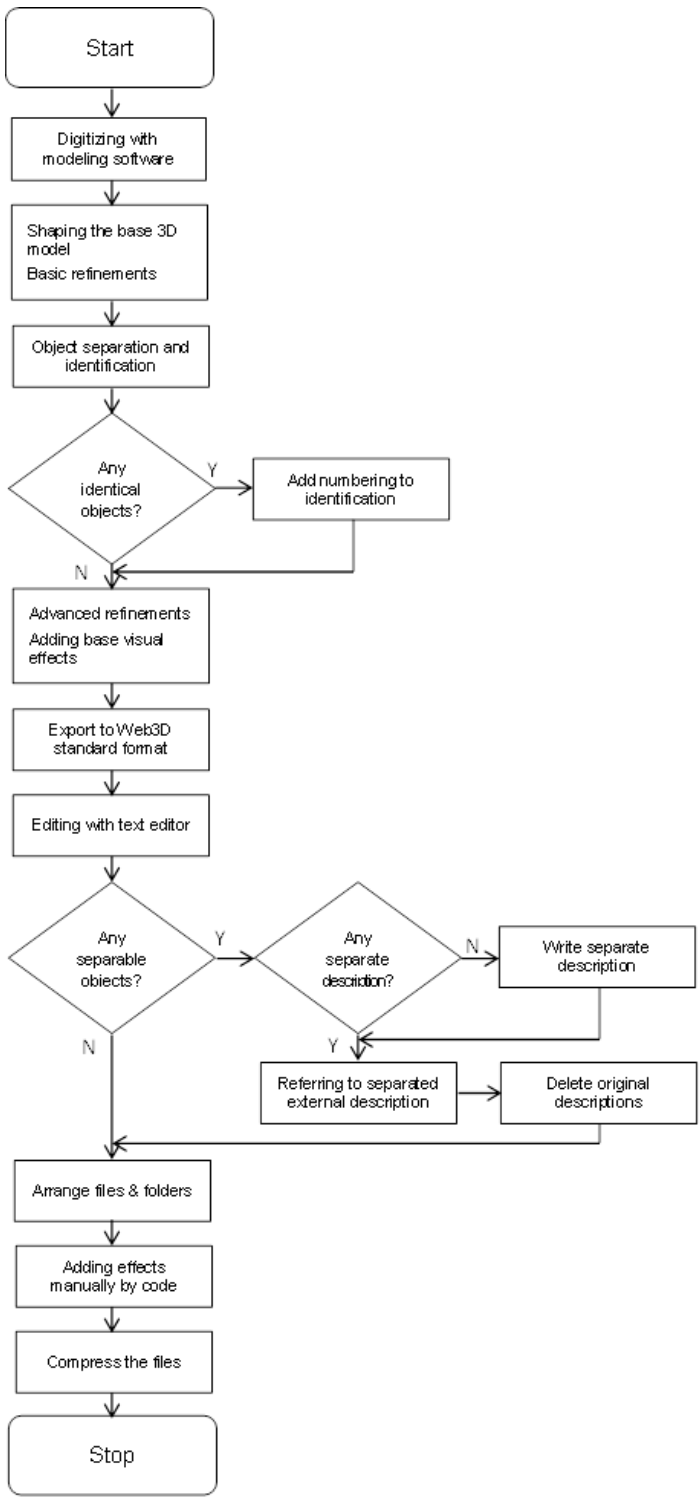

Fig 2: Flowchart which illustrates the method

The method can be described as follows. Creation of Web3D world starts by digitizing the objects using 3D modeling software. The first step is carried out to realize the sketch into 
a digital object based on a certain scale. Once the initial object is created, the next step is to transform the object into base 3D model as the digital visual representative of the real-world object. After that, early refinements are done in order to provide more details in $3 \mathrm{D}$ models according to the existing sections. Next, each constituent objects are separated and given identification. Constituent objects selected in such a way that can be separated as a separate element which can be used again in other parts of the world, or even used in another world when needed. When there is a need to create the same objects and must be described repeatedly (to be copied to another position), then each object is named by a sequence to be easily identified.

Further refinements can be made to establish a model in order to visually correspond to the original object in the real world, including addition of skin or texture to objects. Textures in Web3D can be in the form of still or motion images, or even an application UI [25]. This step is in conjunction with adding basic effects to the scenery (lighting, camera, animation, etc), in order to increase the display realism, or for other needs. This step can use modeling software similar to the previous one or different software, depending on the purposes and the features offered by the software.

After the refinements have been finished, exporting the model to Web3D standard format can be done. If there are properties for conversion process in the modeling software used, they need to be adjusted in advance. This needs to be done especially when a specific type of object has been selected as well as other details correspond to available options, including the level of precision for the coordinates. Prior to export, if the $3 \mathrm{D}$ object is created using of the increased element of realism by utilizing the image file as the skin of the object, then availability of accompanying elements need to be dealt in the form of image files.

The single file as an export result then edited with a text editor software that has the ability to open large files. If separable object usage has been found, and description of the object has been named as well as no separated description file has been found, then the description can be moved to a separate file. The description in the exported files are then removed, leaving the starting position coordinates information, scale, and orientation. Separated element in the file then referred as the replacement of object description that has been deleted.

When a separable object is found and there is a corresponding separated description file, then the description on the exported file is deleted, leaving the starting position coordinates, scale, and orientation information. The separated description file will be referenced by this section later. If the separated file contains the named description, then it can be separated as well to be placed in other separated file and referred by the previous file.

Separated files are arranged in folders as needed, including image files for textures. If the files were moved to other places, then the reference has to be adjusted. LOD, script, and other effects can be added manually by code into the main document. Additional required files can be made and placed in their suitable location. Files can even be placed in a variety of separate servers, so that the principle of distributed world in Web3D technology can be met. After all the files are in their prepared location, then the compression can be done on every file making up the world when required.

\section{DISCUSSIONS}

In order to realize the development process in a short time, the proposed method also requires the use of softwares which are not just text editor. The required software does not have to be a specific software to build Web3D world, it can be a 3D modeling software which is currently widely used and has the ability to export the results in Web3D standard format. It is also necessary to have a text editor which has the ability to read and write large text file, because the result of export is a single file which includes all the contents of the object that is created by $3 \mathrm{D}$ modeling software. Modeling software can not generate separate world files as the result of export. Although external reference on 3D objects which had been placed in a scenery by modeling software can be done, when the software exports the document then all external references will be placed into one single file. The description of all the objects in a single file will make the resulting file size very large.

Optimizing the world document is done by cutting and removing most of contents from the resulting exported document. The same elements that appear repeatedly will have to be removed, leaving just one definition for such $3 \mathrm{D}$ object and then separated from the main document. Therefore, steps that need to be done next are creating the references to this single definition document file and do some adjustments on the scale, location, and orientation as needed. These steps require specific naming for each object when created with $3 \mathrm{D}$ modeling software, so that the object can be recognized once exported into a single document file in VRML format.

Actually, users can manually separate the object model in the scenery made by modeling software and then export it into a separate file. This method is surely able to generate separated files of individual obejct. But when this is done, users will find it hard to put back the object inside the main world, since users must find the exact coordinates value, appropriate scale, and the correct object orientation on its suitable location. Therefore, to ensure precision it is better to utilize the coordinates generated by modeling software. Once exported, then the coordinates can be used to notify the correct placement location to the object that has been separated.

Below is a sample code in VRML after the supporting elements has been identified, ported to separate files, and then referred by the main document. The first line shows direct reference to separated world element, the second line shows a direct reference while in the same time creating an alias for the referenced external element. The alias then used by the third line to make a reference.

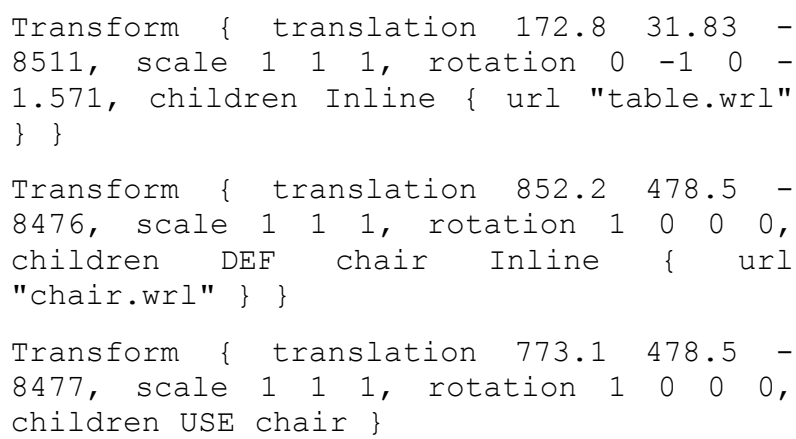

After going through an adjustment, world has a smaller overall document size so it can be transmitted more easily in the network. Adjustments were also made the whole world become modular since the elements are distributed outside the main document. Modularization of components forming the world will reduce the failure rate of loading or damage to the 
visuals or deformation. Potential failure due to problems on the transmission network that may occur when the document files have a very large size can be lowered. Although bandwidth is continuously improving, latency remains an issue [26]. Other than that, initial loading is fast because the document that need to be put into memory is small in size. Furthermore, object definition document can still be further reduced by way of compression using gzip, compression method that uses industry-standard algorithm [27]. Compressed documents are smaller than the original documents so they further lighten the network traffic load.

Before the compression process is executed, optimization can be performed on the document element so as the resulting world will not encumber the browser. Advanced optimization can be simply done by reducing the complexity of existing object geometry, while trying to ensure that the displayed view still have high detail. After that, adjustments to the property such as lighting elements can be performed to the contents of the documents forming the world in order to provide better performance or view.

The series of steps in this method has been used in the development a small sample of world in the form of a classroom along with its ancillary apparatus such as in Fig. 3. Although the world is merely a class room (indoor-type scenery) in the size of $14 \times 10$ square meters, it is consisted of 3D polygonal objects in high detail, with raster images used for object surfaces only. When only relying on exported file produced from the modeling software, the result is a single document file which compiles the whole world, with the size of $130 \mathrm{MB}$. Besides take a relatively long time to pass in the network, computer memory will also be overburdened by the amount of data that must be stored from the network. The browser that displays the world also provides very slow response, and object rendering performance tends to be low. On some computers, the world even failed to appear, although the resulting document of export is in accordance with the standard format.

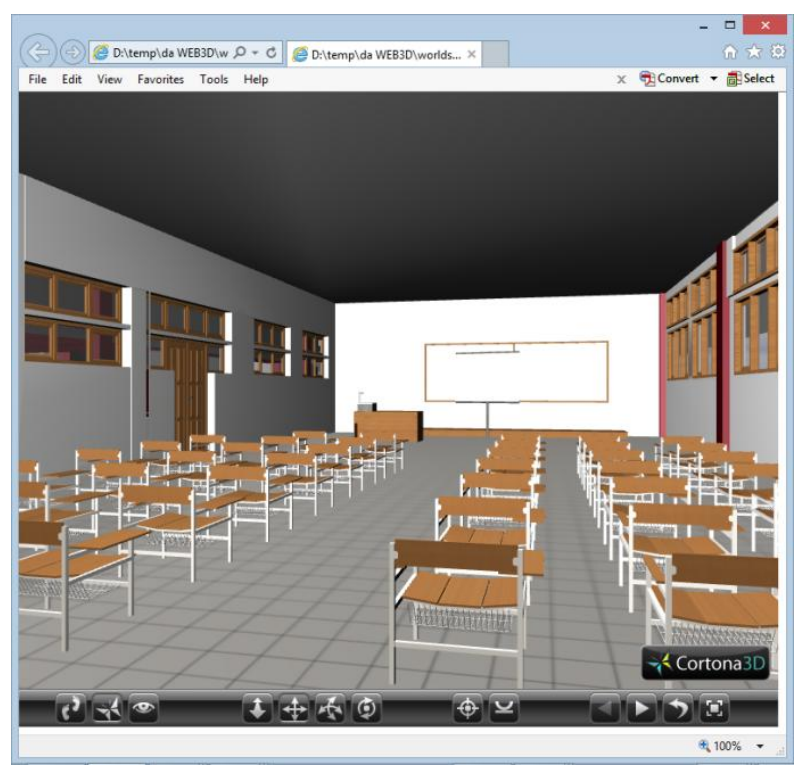

Fig 3: Sample world built for the experiment

Using the method, elements which make up the world have been distributed into 26 files, including image files for the texture of objects. The overall size of the document had declined drastically to $16 \mathrm{MB}$. This decline was achieved since a large number of object-forming codes have been eliminated because some visuals only refer to a description file, eg the seat object as shown in Fig. 4.

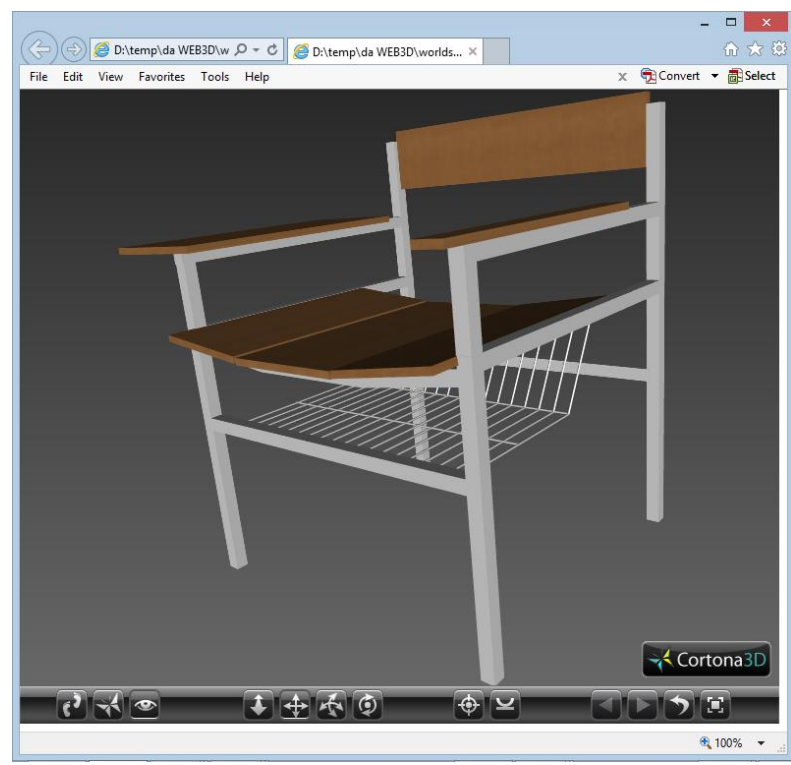

Fig 4: Chair object used in the world

Decrease in file size has brought about faster data transfer within the network. Document loading into memory has become faster with smaller size of files forming the world as well as the main document files which were also very small. There were no loading failure at all on all computers which tries to show this world in their browser. Rendering performance has increased, and this increase can be drastic when the special effects for the optimization purpose have been added, eg using Level of Detail (LOD). Updates to the constituent elements of the world can be easily performed because each component has been separated and can be treated respectively as needed. Therefore, world becomes eligible to be published online on the Internet. Constituent elements of the world that are distributed will also facilitate further development if the users want to throw in a variety of additional features into the world they made to enhance it.

Although the result of experimental sample world were acceptable for online publication, the method still have not touched the interactivity side of the development. Interactivity requires specific handling since it is not just about forming the 3D objects, it is about defining the proper response of the objects when users interact with them. Further enhancement for the proposed method is needed for this purpose.

\section{CONCLUSION}

The proposed world development sequence method can become a guide to help prospective developers or beginners in Web3D technology to quickly produce a site with a world that deserves to be published online. This method assumes that developers are familiar with the 3D modeling software so that the development time can be shortened than without using these tools along with the method. Prospective developers do not have to really understand details of the code in their choosen standard format, they can simply use what has been provided by the modeling software to build a basic yet functional world. Further optimization can be done manually on the resulting document once developers begin to better understand the format that they use. For future development, the proposed method can be further enhanced with focus on user interactivity in order to provide better user experiences when they navigate inside the world. 


\section{ACKNOWLEDGMENTS}

Our thanks to Multimedia and Network Lab of the Department of Information Systems at UAD and Computer Networking Lab of the Department of Computer Science and Electronics at UGM which have provided the resources for our research and experiments.

\section{REFERENCES}

[1] http://oldcda.design.ucla.edu/CAAD/getty/getty.wrz

[2] http://oldcda.design.ucla.edu/CAAD/www.cda.ucla.edu/c aad/rodeo/rodeo1.wrl

[3] Ballam, A. M., 1999. Resurrecting Ikaros. Thesis. College of Art and Architecture, Department of Architecture, University of California at Los Angeles, retrieved from http://oldcda.design.ucla.edu/CAAD/abdul/.

[4] http://www.logon.si/nmlj/nmlj-us.html

[5] http://www.spg.cz/ivan/

[6] http://amarna.cast.uark.edu/index.html

[7] Sperka, M., 2004. Web 3d And New Forms Of Human Computer Interaction. In Proceedings of 2nd International Symposium of Interactive Media Design (ISIMD), Yeditepe University, Istambul, Turkey. Retrieved from http://newmedia.yeditepe.edu.tr/pdfs/isimd_04/24.pdf.

[8] Petridis, P., White, M., Mourkousis, N., Liarokapis, F., Sifniotis, M., Basu, A., Gatzidis, G., 2005. Exploring and Interacting with Virtual Museums. In Proceedings of the 33rd Conference in Computer Applications and Quantitative Methods in Archaeology (CAA), Tomar, Portugal, pp 73-82. Retrieved from http://www.fi.muni.cz/ liarokap/publications/CAA2005.pdf.

[9] Chittaro, L., and Ranon, R., 2007. Web3D technologies in learning, education and training: Motivations, issues, opportunities. Computers \& Education, Volume 49 Issue 1, pp 3-18, Elsevier Science Ltd. Oxford, UK. doi>10.1016/j.compedu.2005.06.002.

[10] Hamza-Lup, F. G., Farrar, S., Leon, E., 2015. Patient specific 3D surfaces for interactive medical planning and training. In Proceedings of the 20th International Conference on 3D Web Technology (Web3D '15), pp 107-113, Heraklion, Crete, Greece. doi $>10.1145 / 2775292.2775294$.

[11] Jung, Y., Recker, R., Olbrich, M., Bockholt, U., 2008. Using X3D for medical training simulations. In Proceedings of the 13th international symposium on 3D web technology (Web3D '08), pp 43-51, Los Angeles, California, USA. doi>10.1145/1394209.1394221.

[12] Pesce, M., 1995. VRML: Browsing \& Building Cyberspace. New Riders Publishing, Indianapolis.

[13] Lemay, L., Couch, J., Murdock, K., 1996. Laura Lemay's Web Workshop: 3D Graphics \& VRML 2.0. Sams Publishing, Indianapolis.

[14] Carey, R., Bell, G., Marrin, C., 1997. ISO/IEC 147721:1997 Virtual Reality Modeling Language (VRML97). The VRML Consortium Incorporated. Retrieved from http://www.vrml.org/Specifications/VRML97.

[15] Web3D Consortium. The Virtual Reality Modeling Language, Part 1-Functional specification and UTF-8 encoding, Amendment 1--Enhanced interoperability. Retrieved from http://www.web3d.org/documents/specifications/147721/V2.1/index.html.

[16] Web3D Consortium. Extensible 3D (X3D), Part 1: Architecture and base components. Retrieved from http://www.web3d.org/documents/specifications/197751/V3.2/Part01/Architecture.html.

[17] Isenburg, M., Snoeyink, J., 2002. Coding with ASCII: compact, yet text-based 3D content. In Proceedings of the 1st International Symposium on 3D Data Processing, Visualization and Transmission (Invited Paper), Padova, Italy, pp 609-616. Retrieved from https://www.cs.unc.edu/ isenburg/papers/is-cwa-02.pdf.

[18] Web3D Consortium. X3D Specifications - ISO/IEC19776-1. Retrieved from http://www.web3d.org/standards/number/19776-1.

[19] Hosoya, H., Pierce, B., 2003. XDuce: A statically typed XML processing language. ACM Transactions on Internet Technology (TOIT), Volume 3 Issue 2 May 2003, pp 117-148, New York, USA doi $>10.1145 / 767193.767195$.

[20] Web3D Consortium, X3D Specifications - ISO/IEC19776-2. Retrieved from http://www.web3d.org/standards/number/19776-2.

[21] http://www.parallelgraphics.com/products/vrmlpad.

[22] https://savage.nps.edu/X3D-Edit/X3D-Edit3.3.zip.

[23] Kostic, Z., Radakovic, D., Cvetkovic D., Trajkovic S., Jevremovic A., 2012. Comparative Study of CAD Software, Web3D Technologies and Existing Solutions to Support Distance-Learning Students of Engineering Profile. IJCSI International Journal of Computer Science Issues, Vol. 9 Issue 4 No 2, Doolar Lane, Mahebourg, Republic of Mauritius.

[24] Jeginovic, S., 2004. Interactive 3D models - From 3ds max to VRML. In Proceedings of 8th Central European Seminar on Computer Graphics (CESCG 2004), Budmerice Castle, Slovakia. Retrieved from www.cescg.org/CESCG-2004/papers/54_JeginovicSanjin.pdf.

[25] Jung, Y., Webel, S., Olbrich, M., Drevensek, T., Roth, M., Fellner, D., 2010. Interactive textures as spatial user interfaces in X3D. In Proceedings of the 15th International Conference on Web 3D Technology (Web3D '10), pp 147-150, Los Angeles, California, USA. doi>10.1145/1836049.1836071.

[26] Mwalongo, F., Krone, M., Karch, G., Becher, M., Reina, G., Ertl, T., 2014. Visualization of molecular structures using state-of-the-art techniques in WebGL. In Proceedings of the 19th International ACM Conference on 3D Web Technologies (Web3D '14), pp 133-141, Vancouver, British Columbia, Canada. doi>10.1145/2628588.2628597.

[27] Fararjeh, A. M. A., Jabal, A. M. A., 2010 Recommendations to improve performance of an enterprise web-based application. In Proceedings of the 1st International Conference on Intelligent Semantic Web-Services and Applications, Article No. 29, Amman, Jordan. doi>10.1145/1874590.1874619. 